\title{
Quantitative damage-benefit evaluation of drug effects: major discrepancies between the general population, users and experts
}

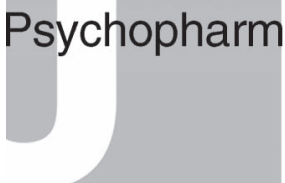

\author{
Michel Reynaud 1,2,3, Amandine Luquiens ${ }^{1,2,3}$, Henri-Jean Aubin 1,2,3, \\ Céline Talon ${ }^{4}$ and Catherine Bourgain ${ }^{5,6}$
}

Journal of Psychopharmacology 27(7) 590-599

(C) The Author(s) 2013

Reprints and permissions:

sagepub.co.uk/journalsPermissions.nav DOI: $10.1177 / 0269881113487809$ jop.sagepub.com

(S)AGE

\begin{abstract}
Aims: This study sought to quantify the perceptions of damage and benefit, for users and society, associated with five addictive substances (alcohol, tobacco, cannabis, cocaine and heroin) and one addictive behavior (gambling), in a large sample representative of the French population. We compared with expert assessments and investigated the effects of substance consumption on these perceptions.

Findings: The ranking of substances by the lay public is very divergent from that of experts. The public overestimates damage to users and to society and underestimates the benefit, in comparison with experts, for all substances. Alcohol is the only exception, with damage and benefit perceptions similar to those of experts. Heroin and cocaine are perceived as the two most dangerous substances. The damage of cannabis and alcohol are judged to be equivalent. The three legal substances are associated with the highest overall benefit, although cannabis has the highest perceived benefit for users. Substances with the highest perceived benefit tend to be associated with perception of lower levels of damage. Individuals with an history of substance use have a perception of the damage and the benefit for that substance which is more congruent with experts, including a similar ranking of substances.

Conclusions: Prevention campaigns focused on perceptions of damage alone have reached their limits. The perception of benefit should be taken into account in early interventions with illegal substance users.
\end{abstract}

Keywords

Damage/benefit assessment, substance use, general population

\section{Introduction}

To improve guidance to policy makers concerning health, policing and social care, a number of studies have been conducted to assess the harm associated with different addictive substances using evidence-based scales (Bourgain et al., 2012; Nutt et al., 2007, 2010; Van Amsterdam et al., 2010). In these studies, all experts quantitatively scored different criteria for harm, which ranged from the damage inflicted by substance use on users to the damage inflicted on society by substance use. Interestingly, the results obtained from experts of different nationalities were highly concordant, despite the fact that there were slight differences in the procedures between studies. Alcohol, by far, appears to be the most harmful substance of those evaluated, more harmful than heroin. The first publication to show a discrepancy between the harmfulness of substances and their legal statuses (Nutt et al., 2007) yielded much controversy among both scientists and the public at large (Obot, 2011). The views of scholars in the field that legal substances could cause more harm to society than illegal drugs were in contradiction to the general opinion of policy makers and the general population (Costes et al., 2010; Rossow, 2011).

To our knowledge, however, the various national surveys (Blendon and Young, 1998; Costes et al., 2010; Storvoll et al., 2010), which are regularly conducted to measure public perceptions on addictive substances, only ask for general views regarding substance use and do not include quantitative measurements of the different effects of substance use. Thus, precise and quantitative comparisons of the perceptions of lay people and experts could not be conducted. Furthermore, substances are only considered from the standpoint of the damage associated with their consumption and not from that of their potential benefit, although balancing the damage and benefit associated with an addictive substance is an effective therapeutic approach for patients with substance use disorders (Miller and Rollnick, 2002).

In the quantitative evaluation of drug effects that we conducted with French experts in addiction (Bourgain et al., 2012), we developed a new and simple grid that included 12 criteria that covered the entire spectrum of damage and benefit associated with substance use. The results obtained with this simple grid were highly correlated with a previous evaluation of damage obtained with an expert consensus-based procedure (Nutt et al., 2010). The correlation coefficient for the seven substances common to the two studies was 0.95 . Furthermore, our study pointed out that the global

${ }^{1}$ INSERM, UMR 669, Villejuif, France

2Université Paris Sud, Villejuif, France

${ }^{3}$ Hôpital Paul Brousse, Villejuif, France

4Ipsos Santé, Paris, France

${ }^{5}$ Inserm U988, Villejuif France

${ }^{6}$ CNRS UMR8211, EHESS, Université Paris Descartes, Villejuif, France

Corresponding author:

Michel Reynaud, Department of Psychiatry and Addiction Medicine, Paul Brousse Hospital, 12/14 Avenue Paul Vaillant Couturier, Villejuif, F-94804, France.

Email: michel.reynaud@pbr.aphp.fr 
opinion of experts on a given addictive substance is strongly influenced by their perception of the benefit associated with the consumption of that substance.

In the present study, we used the same damage and benefit grid to quantitatively evaluate the perceptions of the general population on five addictive substances, alcohol, tobacco, cannabis, cocaine and heroin, with high consumption prevalence in Europe, respectively $76 \%, 29 \%, 6.8 \%, 1.2 \%$ and $0.5 \%$ for their past year consumption (Eurobarometer, 2010a, 2010b; European Monitoring Centre for Drugs and Drug Addiction (EMCDDA), 2010, 2012). One common addictive behavior proposed recently for inclusion among addictions in the future Diagnostic and Statistical Manual of Mental Disorders, version 5 (DSM-5) was also included in the study: gambling. A representative panel of 1016 individuals, aged 18-64 years, was interviewed using an online questionnaire. The quantitative measurements of damage and benefit perceived by this population were compared with those perceived by experts (Bourgain et al., 2012), and the effects on the perceptions associated with a past year consumption experience were investigated separately for each substance.

\section{Methods}

\section{Survey instrument}

The online questionnaire evaluated the perceived damage and benefit associated with the consumption of five addictive substances (alcohol, tobacco, cannabis, cocaine and heroin) and one addictive behavior (gambling). For simplicity, we will refer to gambling as a 'substance'.

'Overall damage' was decomposed into six sub-types of damage. Three covered the spectrum of damage to the substance user (referred to as 'user damage' in what follows), i.e. acute health damage, chronic health damage and dependence, while the remaining three covered the damage to society ('social damage'), i.e. health and social costs, legal costs and the social consequences of dysfunctional behavior.

The entire spectrum of the potential beneficial effects of substances ('overall benefit') were also decomposed into six sub-types. Three sub-types of benefit were associated with substance consumption ('user benefit'), i.e. hedonistic benefit, identity benefit and auto-therapeutic benefit, and three subtypes of benefit were associated with society ('social benefit'), i.e. economic benefit, social benefit and cultural benefit. The definitions of these 12 criteria were those developed by Bourgain et al. (2012) and validated by the executive committee of the French Federation on Addiction, with minor adaptations for use with a panel of lay people. Descriptions of the criteria are presented in the supplementary information section (Supplementary Material, Table S1).

For each criterion, the questionnaire included a visual analogue scale (VAS) that ranged from 0 ('no damage'/'no benefit') to 10 ('extreme damage'/'intense benefit' or 'highly significant benefit') on which the panelists were asked to place six boxes corresponding to each of the six substances. The use of a single scale to evaluate all substances facilitated comparisons between substances in the scoring of each criterion.

The effects of order response bias were controlled for by the random allocation of user and social criteria in the first section of the online questionnaire and damage and benefit criteria in the first sub-section. Four different substance orders were also randomly assigned to the panelists.

The questionnaire began with questions on the five sociodemographic characteristics used as stratification variables (see below) and ended with a question on consumption habits for each of the six substances with the following possible responses: consumption in the past month; occasionally during the past year; from time to time in the past; only tested; quit or never consumed.

\section{Sampling procedure}

The sample was randomly selected from an online research panel of more than 619,000 individuals representative of the French general population developed and maintained by Ipsos Interactive Services (Gentilly, France), a survey research firm (http://www. ipsos-interactive.com/). Panelists were invited by email to participate in an 'academic survey organized by the French National Institute for Medical and Scientific Research' dealing 'with perceptions of different addictive behaviors: gambling, alcohol, tobacco, cannabis, cocaine and heroin'. A sample size of 1016 was calculated to yield a maximum margin of sampling error of \pm 3.1 percentage points for an overall percentage of $50 \%$. To be eligible, panelists had to be aged 18-64 years and could not have responded to a survey on addictive substances in the last 12 weeks or to more than six surveys in the last four weeks. To limit coverage bias, random sampling was stratified to match official French census statistics for gender, age, occupation, population in the area of residence and region of residence. To limit selection bias, panelists with low response rates were oversampled relative to others, e.g. 50 panelists with a $1 \%$ chance of taking the survey were randomly drawn for every one panelist with a $50 \%$ chance of taking the survey (Schwarzinger et al., 2010).

The sample stratification was performed using external data collected regularly on the panelists and made available for the present analysis by courtesy of Ipsos Interactive Services. A crossvalidation was also performed using the socio-demographic questions included in the online questionnaire.

The Ipsos panel was approved by the National Data Protection Authority (Commission Nationale Informatique et Libertés (CNIL)) which is in charge of ethical issues and the protection of individual data collection in France. The survey was conducted 4-24 January 2012.

\section{Expert evaluations}

The evaluations of damage by experts that were used for comparison with the evaluations by the general population are published in Bourgain et al. (2012). Briefly, 48 French experts, all board members of the French Federation on Addiction, were recruited in May 2010 to participate in the evaluation of nine addictive substances (alcohol, tobacco, gambling, cannabis, cocaine, heroin, amphetamines, ecstasy and other synthetic drugs). Two weeks before the evaluation, they received a list of publications in high impact journals and important reports for each substance, including gambling, available from a website. Each expert was instructed to complete a questionnaire individually that included VASs to quantify the same 12 criteria for damage and benefit as those used in the present study and additional measurements of their general opinion on the substances. 


\section{Statistical analysis}

The mean values of VAS scores were used to summarize the information on the 12 criteria. For clarity and simplicity, composite scores were also computed for each substance. The user damage scores were obtained by summing the mean values of the three criteria corresponding to the damage to the substance users and the societal damage scores were obtained by summing the mean values of the three criteria corresponding to the damage to society. Both ranged from 0-30. Overall damage scores were also calculated by summing the corresponding user and societal scores. With a range of $0-60$, these overall scores give equal importance to the user and societal dimensions of harm, consistent with previous studies (Bourgain et al., 2012; Nutt et al., 2010). Similarly, user benefit scores were computed by summing the mean values of the three criteria corresponding to the benefit for the substance users ( $0-30$ scale), societal benefit scores were created by summing the mean values of the three criteria corresponding to the benefit to society ( $0-30$ scale), and overall benefit scores were created by summing the corresponding user and societal benefit scores $(0-60$ scale).

User, societal and overall scores were computed for the sample group consisting of 1016 individuals. For each substance, these composite scores were also calculated for the group of panelists who had reported a consumption of this particular substance within the past year (user group) and for the group of panelists who reported the absence of consumption of this substance in the past year (non-user group). The groups of users and non-users were thus different for each substance.

The comparisons between these composite scores and those evaluated by experts, taken as the reference in this study, were conducted with classical Student's $t$-tests. To account for the 108 Student $t$-tests performed (18 tests for each of the six substances), the threshold of significance was adjusted using a Bonferroni correction. A global type I error of 5\% over all tests was achieved when a $p$-value smaller than $4.6 \times 10^{-4}$ is applied to each individual test.

All analyses were performed using R software for statistical analyses (R Development Core Team, 2011).

\section{Results}

\section{Sample characteristics}

The socio-demographic characteristics of the 1016 panelist sample are presented in Table 1. Table 2 displays the number of panelists reporting an experience of past year consumption or non-consumption for each of the six substances. The corresponding sample prevalence data are also included in Table 2, together with the national prevalence data reported by the French Observatory of Drugs and Addictions (FODA) and based on a 2010 survey that included 27,653 individuals aged 11-75 (Beck et al., 2011; Pousset, 2012). Prevalences are concordant for alcohol $(83 \%$ in our study vs $84 \%$ in FODA), tobacco $(30 \%$ vs $32 \%)$ and cocaine $(0.6 \%$ vs $0.8 \%)$. Consumption reports are lower than the national data for cannabis ( $4.5 \%$ vs $7.7 \%)$ and higher for gambling ( $42 \%$ vs $32 \%)$. The difference in age range between the two studies could be the explanation for these discrepancies since the FODA survey included young people aged 11-17 years among which the prevalence of cannabis is high but that of gambling is
Table 1. Socio-demographic characteristics of the 1016 panelist sample.

\begin{tabular}{lr}
\hline Mean age (years) & 40.3 \\
Men & $51 \%$ \\
Living place & \\
$\quad$ Town<20,000 & $41 \%$ \\
Town 20,000-200,000 & $18 \%$ \\
City>200,000 & $41 \%$ \\
Graduation & \\
$\quad$ High school & $72 \%$ \\
$\quad$ University & $12 \%$ \\
Employment status & \\
$\quad$ Manual labor & $27 \%$ \\
Clerical position & $31 \%$ \\
Managerial position & $15 \%$ \\
Self-employed & $6 \%$ \\
Retired or unemployed & $21 \%$ \\
\hline
\end{tabular}

low. None of the panelists of our sample declared consumption of heroin in the past year.

\section{Damage scores}

The quantitative assessment of substance harm by lay people was globally consistent with the legal status of the substances (Figure 1 and Table 3). Heroin and cocaine were assessed as the two most dangerous substances (mean overall damage scores of 55.78 and 54.91 , respectively), while cannabis and alcohol were rated equally and were considered the third most dangerous substances (mean overall scores of 47.29 and 47.33, respectively), followed by tobacco and gambling (mean overall scores of 42.1 and 33.7, respectively). The high overall scores associated with heroin and cocaine were not driven by a particular dimension of harm, as all six damage criteria included in the study were quantitatively higher than those for alcohol. Similarly, cannabis and alcohol were associated with equivalent levels of harm, for all six criteria.

Comparisons of the panelists' responses with expert evaluations (Figure 1 and Table 3) showed two interesting results. First, the overall damages associated with cannabis, gambling, cocaine, tobacco and heroin were significantly higher when evaluated by lay people (scores were $+51 \%,+49 \%,+42 \%,+32 \%$ and $+24 \%$ above those of experts, respectively). These overestimations were not specific to a particular dimension, as all user and societal scores were significantly above the corresponding score of experts. Second, the damage associated with alcohol was similar to that assessed by experts (global score of 48.11 for the experts and 47.33 for the population sample), the similarity being particularly strong for the damage to users (user scores of 24.08 for experts and 24.44 for the population).

The evaluations of substance damage by the subgroups of individuals reporting consumption of the corresponding substances in the past year were systematically lower than those by the subgroups of substance non-users (Figure 2, Table 3) and were globally closer to the expert evaluations. The overall scores from cannabis, cocaine and alcohol users were congruent with those of experts (scores were, respectively, $+6 \%$ and $+9 \%$ above those of experts for cannabis and cocaine user and $-2 \%$ below that of experts for alcohol). Although significantly different, the overall 
Table 2. Number of panelists reporting consumption/no consumption within the past year for the six substances. These numbers correspond to the sample sizes of the different 'user' and 'non user' groups. Corresponding past year consumption prevalence estimated from our sample and from the French Observatory of Drugs and Addictions survey (source: Pousset, 2012).

\begin{tabular}{|c|c|c|c|c|}
\hline & \multicolumn{2}{|c|}{ Number of panelists declaring, past year } & \multicolumn{2}{|c|}{ Past year consumption prevalence } \\
\hline & $\begin{array}{l}\text { Consumption } \\
\text { (User group) }\end{array}$ & $\begin{array}{l}\text { No consumption } \\
\text { (Non-user group) }\end{array}$ & Our sample & $\begin{array}{l}\text { French Observatory of } \\
\text { Drugs and Addictions }\end{array}$ \\
\hline Alcohol & 843 & 173 & $83 \%$ & $84 \%$ \\
\hline Gambling & 306 & 710 & $30 \%$ & $32 \%$ \\
\hline Tobacco & 429 & 587 & $42 \%$ & $32 \%$ \\
\hline Cannabis & 45 & 971 & $4.5 \%$ & $7.7 \%$ \\
\hline Cocaine & 6 & 1010 & $0.6 \%$ & $0.8 \%$ \\
\hline Heroin & 0 & 1016 & NA & NA \\
\hline
\end{tabular}

NA: not available.

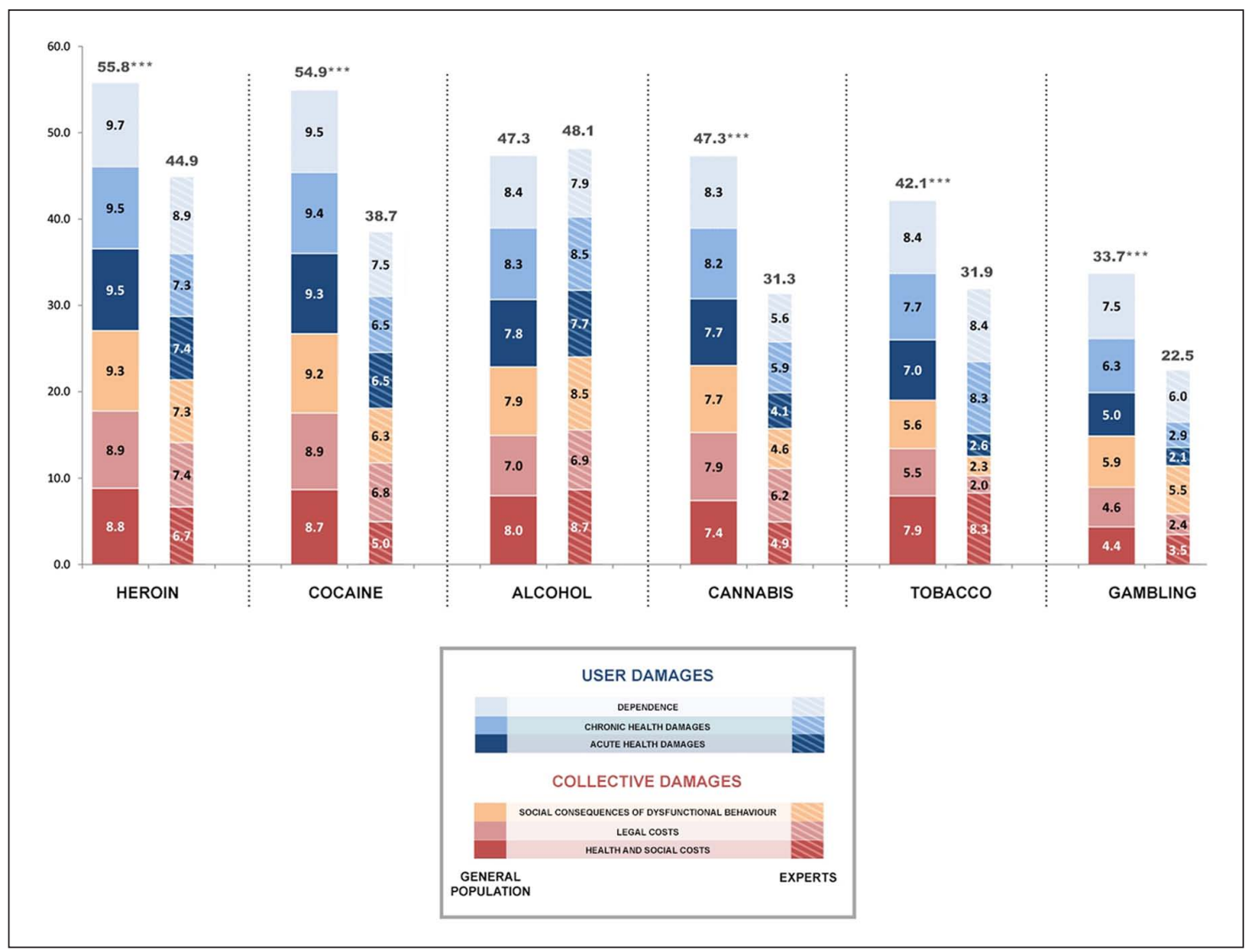

Figure 1. Substance damage scores as evaluated by the general population and by experts. User damage criteria are clustered at the top of the bars (shown in blue), while social damage criteria are clustered at the bottom of the bars (shown in red). Overall damage score values are shown above the bars, with ${ }^{* * *}$ when their evaluations by the general population are significantly different from those by experts $\left(t\right.$-test with $p$-value $\left.<10^{-10}\right)$. Expert data are from Bourgain et al. (2012).

scores by tobacco and gambling users were closer to the experts' scores than the non-users' scores. Altogether, the correlation coefficient between overall damage scores by substance users and by experts was 0.94 (for all substances except heroin for which no data were available). Overall scores were significantly higher for non-users than for experts, for all substances (with the exception of alcohol) as follows: gambling ( $+57 \%)$, cannabis $(+53 \%)$, cocaine $(+42 \%)$, tobacco $(+35 \%)$ and heroin $(+24 \%)$ and the corresponding correlation coefficient was 0.72 .

\section{Benefit scores}

The overall benefit scores were below the mean level $(<30)$ for all substances (Table 4, Figure 3), varying from 19 for heroin to 29.8 
Table 3. Overall damage, user damage and social damage as evaluated by the general population, past-year substance users, past-year substance non-users and experts. The sample size of the user and non-user groups are those of Table 2.

\begin{tabular}{|c|c|c|c|c|c|c|c|}
\hline & & Heroin & Cocaine & Alcohol & Cannabis & Tobacco & Gambling \\
\hline \multirow[t]{4}{*}{ Overall damage score } & General population & $55.8^{\mathrm{a}}$ & $54.9^{a}$ & 47.3 & $47.3^{\mathrm{a}}$ & $42.1^{\mathrm{a}}$ & $33.7^{a}$ \\
\hline & Users & NA & 42.3 & 47.0 & 33.4 & $39.7^{a}$ & $31.2^{b}$ \\
\hline & Non-users & $55.8^{\mathrm{a}}$ & $55.0^{\mathrm{a}}$ & 48.6 & $47.9^{\mathrm{a}}$ & $43.1^{\mathrm{a}}$ & $35.5^{\mathrm{a}}$ \\
\hline & Experts (Bourgain et al., 2012) & 44.9 & 38.7 & 48.1 & 31.4 & 31.9 & 22.6 \\
\hline \multirow[t]{4}{*}{ User damage score } & General population & $28.7^{\mathrm{a}}$ & $28.2^{\mathrm{a}}$ & 24.4 & $24.3^{\mathrm{a}}$ & $23.1^{\mathrm{a}}$ & $18.8^{\mathrm{a}}$ \\
\hline & Users & NA & 22.2 & 24.3 & 17.2 & $22.1^{b}$ & $17.7^{\mathrm{a}}$ \\
\hline & Non-users & $28.7^{\mathrm{a}}$ & $28.2^{\mathrm{a}}$ & 25.1 & $24.6^{\mathrm{a}}$ & $23.5^{\mathrm{a}}$ & $19.6^{\mathrm{a}}$ \\
\hline & Experts (Bourgain et al., 2012) & 23.5 & 20.6 & 24.1 & 15.6 & 19.4 & 11.1 \\
\hline \multirow[t]{4}{*}{ Social damage score } & General population & $27.1^{\mathrm{a}}$ & $26.7^{\mathrm{a}}$ & 22.9 & $23.0^{\mathrm{a}}$ & $19.0^{\mathrm{a}}$ & $14.9^{b}$ \\
\hline & Users & NA & 20.2 & 22.8 & 16.2 & $17.6^{\mathrm{a}}$ & 13.5 \\
\hline & Non-users & $27.1^{\mathrm{a}}$ & $26.8^{\mathrm{a}}$ & 23.5 & $23.4^{\mathrm{a}}$ & $19.6^{\mathrm{a}}$ & $15.9^{b}$ \\
\hline & Experts (Bourgain et al., 2012) & 21.4 & 18.1 & 24.0 & 15.8 & 12.5 & 11.5 \\
\hline
\end{tabular}

NA: not available.

Evaluations by users (or non-users) and by experts are significantly different, a with a $p$-value $<10^{-10}$, bith a $p$-value $<10^{-4}$.

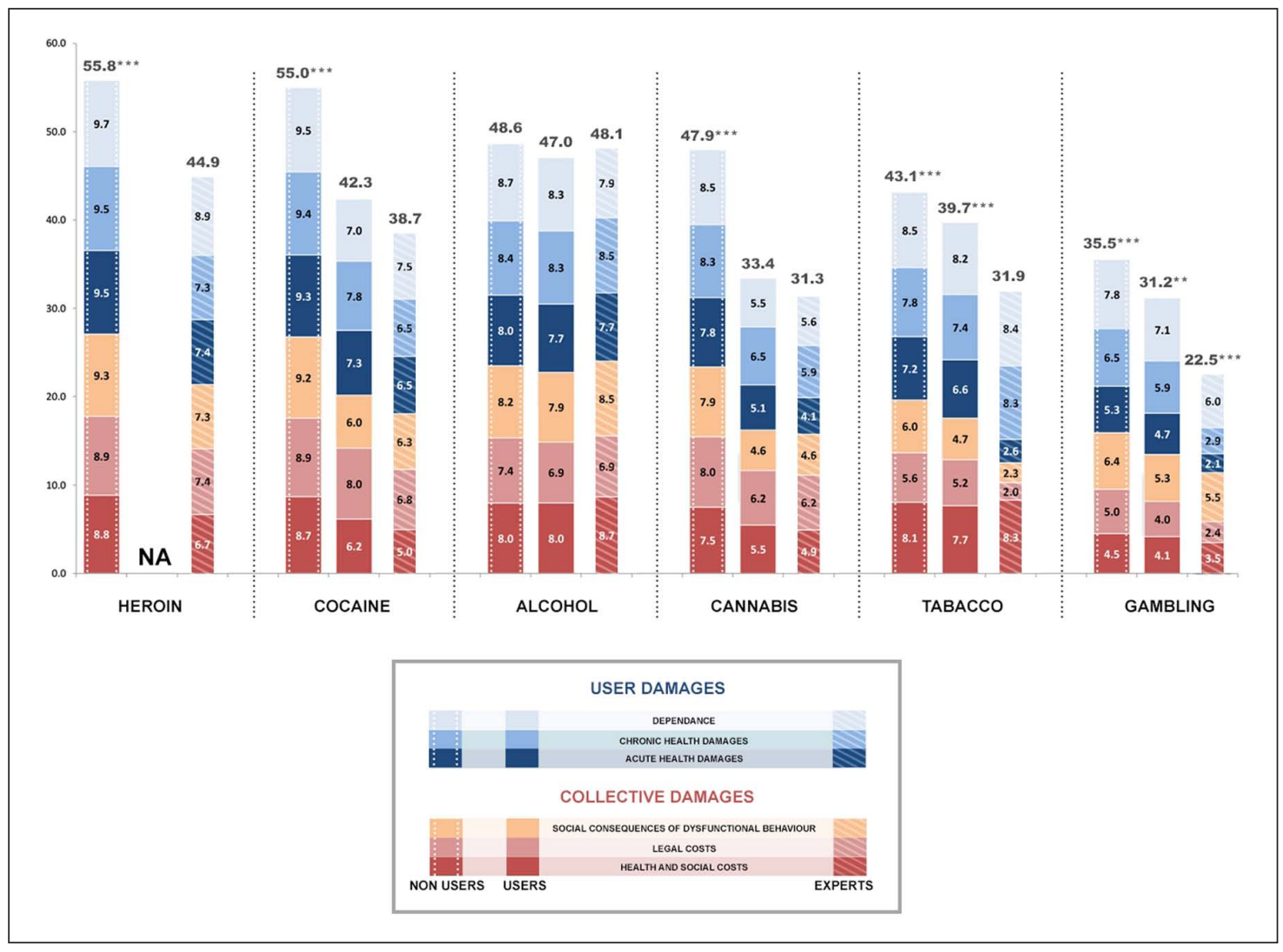

Figure 2. Substance damage scores as evaluated by non-users of the corresponding substance, users of the corresponding substance and experts. User damage criteria are clustered at the top of the bars (shown in blue) and social damage criteria are clustered at the bottom of the bars (shown in red). Overall damage values are shown above the bars, with *** when their evaluations by the substance users (or non-users) are significantly different from those by experts, $t$-test with $p$-value $<10^{-10}$, and ${ }^{* *}$ for $t$-test with $p$-value $<10^{-5}$. Expert data are from Bourgain et al. (2012). Sample size of the users and non-users groups for each substance are those of Table 2. NA: no user available in the sample.

for alcohol (to be contrasted with a variation range of the overall damage scores of 33.68 (for gambling) to 55.78 (for heroin)). The three substances associated with the highest benefit were all legal (alcohol and tobacco overall scores $=27$, gambling overall score $=25.1$ ). However, this ranking was due primarily to higher societal benefit, particularly economic and social benefit, rather than higher user benefit. Indeed, the substance with the highest user benefit score was cannabis (14.5). 
Table 4. Overall benefit, user benefit and social benefit as evaluated by the general population, past-year product users, past-year product nonusers and experts. The sample size of the user and non-user groups are those of Table 2.

\begin{tabular}{|c|c|c|c|c|c|c|c|}
\hline & & Heroin & Cocaine & Alcohol & Cannabis & Tobacco & Gambling \\
\hline \multirow[t]{4}{*}{ Overall benefit score } & General population & $19.0^{\mathrm{b}}$ & $19.7^{\mathrm{b}}$ & $29.8^{a}$ & $24.5^{b}$ & $27.0^{\mathrm{b}}$ & 25.1 \\
\hline & Users & NA & 27.7 & $30.3^{\mathrm{a}}$ & 34.9 & 29.4 & 26.1 \\
\hline & Non-users & $19.0^{\mathrm{b}}$ & $19.7^{\mathrm{b}}$ & $26.5^{\mathrm{a}}$ & $24.2^{\mathrm{b}}$ & $26.2^{\mathrm{b}}$ & 24.2 \\
\hline & Experts (Bourgain et al., 2012) & 25.0 & 26.7 & 45.5 & 31.1 & 34.3 & 28.8 \\
\hline \multirow[t]{4}{*}{ User benefit score } & General population & $12.1^{\mathrm{a}}$ & $12.5^{\mathrm{a}}$ & $13.9^{\mathrm{a}}$ & $14.5^{\mathrm{a}}$ & $12.4^{\mathrm{b}}$ & 11.0 \\
\hline & Users & NA & 17.2 & $14.2^{\mathrm{a}}$ & 18.8 & 13.4 & 11.2 \\
\hline & Non-users & $12.1^{\mathrm{a}}$ & $12.4^{\mathrm{a}}$ & $12.4^{\mathrm{a}}$ & $14.4^{\mathrm{a}}$ & $12.1^{b}$ & 10.7 \\
\hline & Experts (Bourgain et al., 2012) & 18.3 & 18.4 & 21.5 & 19.6 & 16.3 & 12.7 \\
\hline \multirow[t]{4}{*}{ Social benefit score } & General population & 6.9 & 7.2 & $15.9^{\mathrm{a}}$ & 10.0 & 14.6 & 14.1 \\
\hline & Users & NA & 10.5 & $16.1^{\mathrm{a}}$ & 16.1 & 16.0 & 14.9 \\
\hline & Non-users & 6.9 & 7.3 & $14.1^{\mathrm{a}}$ & 9.8 & $14.1^{\mathrm{b}}$ & 13.5 \\
\hline & Experts (Bourgain et al., 2012) & 6.7 & 8.3 & 24.0 & 11.5 & 18.0 & 16.1 \\
\hline
\end{tabular}

NA: not available.

Evaluations by users (or non-users) and by experts are significantly different, a with a $p$-value $<10^{-10}$, b with a $p$-value $<10^{-4}$.

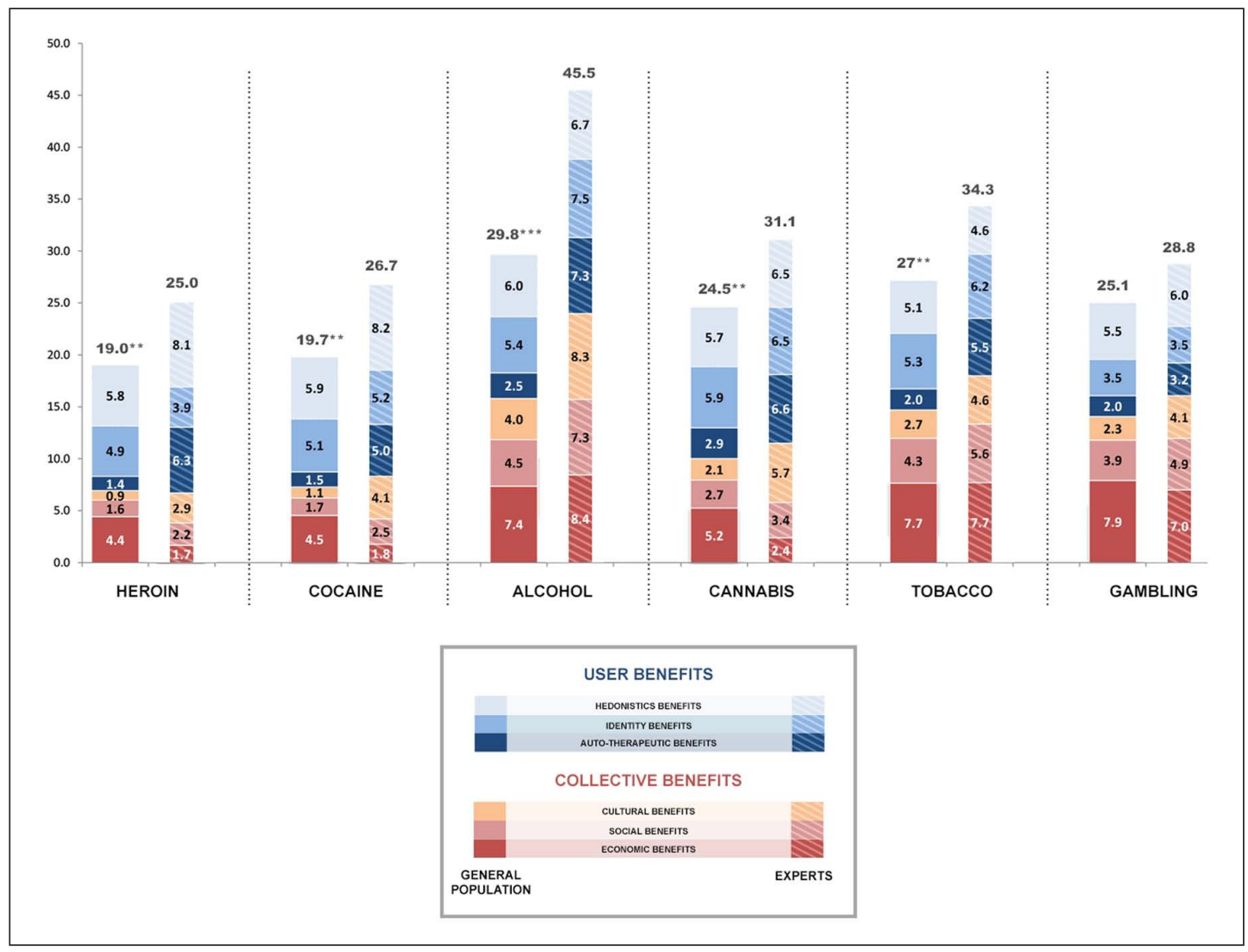

Figure 3. Benefit scores associated with substance use as evaluated by the general population and by experts. User benefit criteria are clustered at the top of the bar (shown in blue), and social benefit criteria are clustered at the bottom of the bar (shown in red). Overall benefit values are shown above the bars, with ${ }^{* * *}$ when the evaluations by the general population was significantly different from those by experts, $t$-test with $p$ value $<10^{-10}$, and ** for $t$-test with $p$-value $<10^{-5}$. Expert data are from Bourgain et al. (2012).

The overall benefit scores for all substances were below the experts' scores $(-35 \%$ for alcohol, $-26 \%$ for cocaine, $-24 \%$ for heroin, $-21 \%$ for cannabis and tobacco, and $-13 \%$ for gambling).
These differences were primarily the result of the differing perceptions on user benefit (user benefit scores were significantly different for all substances except gambling) rather than societal benefit 


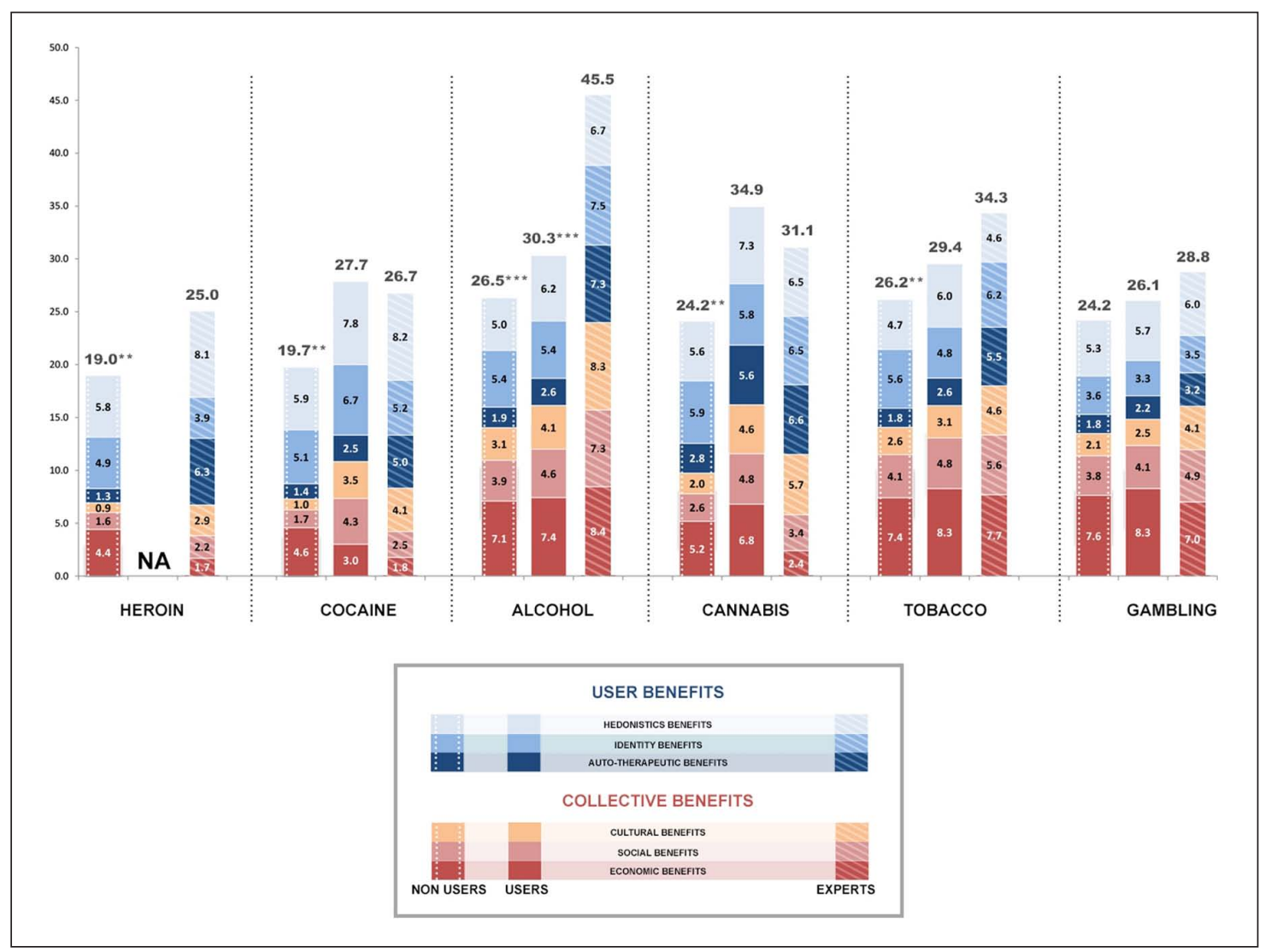

Figure 4. Substance benefit as evaluated by non-users of the corresponding substance, users of the corresponding substance and experts. User benefit criteria are clustered at the top of the bars (shown in blue) and social benefit criteria are clustered at the bottom of the bar (shown in red). Overall benefit values are shown above the bars, with *** when evaluations by the users (or non-users) are significantly different from those by experts, $t$-test with $p$-value $<10^{-10}$, and ${ }^{* *} t$-test with $p$-value $<10^{-5}$. Expert data are from Bourgain et al. (2012). Sample size of the users and nonusers groups for each substance are those of Table 2. NA: no user available in the sample.

(societal benefit scores were not significantly different for any of the substances, with the exception of alcohol). The existence of auto-therapeutic benefit appeared to be largely under-considered by the general population in comparison with experts. The mean scores for this type of benefit ranged from 1.4 for heroin to 2.9 for cannabis among the general population, whereas the scores ranged from 3.2 for gambling to 7.3 for alcohol among the experts.

The overall benefit scores in the subgroups of individuals reporting consumption of the corresponding substances in the past year were systematically greater than those in the subgroups of substance non-users (Figure 4, Table 4). The overall scores by experts and users were not significantly different for any of the substances, with the exception of alcohol. The congruence was particularly good for the user benefit scores (user benefit scores by users are $-4 \%$ below those by experts for cannabis, $-7 \%$ for cocaine, $-12 \%$ for gambling and $-18 \%$ for tobacco). Alcohol was an exception, with both user and societal scores significantly lower than those of experts (user score by alcohol users $-34 \%$ below that by experts, societal score by alcohol users $-33 \%$ below that by experts). At the other end of the spectra, gambling was characterized by relatively close assessments of benefit by users and non-users, both not statistically different from expert measurements.

\section{Correlations between damage and benefit scores}

The correlations between the overall damage scores and the overall benefit scores as estimated by both the general population and by the experts are represented on Figure 5. For the general population, the correlation coefficient between damage and benefit scores is -0.60 . The substances associated with the highest damage tend to have the lowest perceived benefit. Alcohol and gambling appear however to be outliers. The perception of alcohol benefit is particularly high given the level of damage associated to the substance. For comparison, cannabis with a similar damage score, has a benefit score five points smaller (29.8 vs 24.5). Gambling, on the contrary, is the substance with the lowest damage score, but with a relatively low benefit score, equivalent to that of cannabis (25.1 vs 24.5). When these two outlying substances are not taken into account, the correlation coefficient between overall damage and overall benefit scores, is remarkably high: -0.99 . The relation between expert perception of damage and benefit is not so clear cut. The correlation coefficient between damage and benefit scores computed with all substances is even positive $(+0.34)$. However, when the similarly outlying alcohol and gambling are left out, the correlation coefficient drops to 


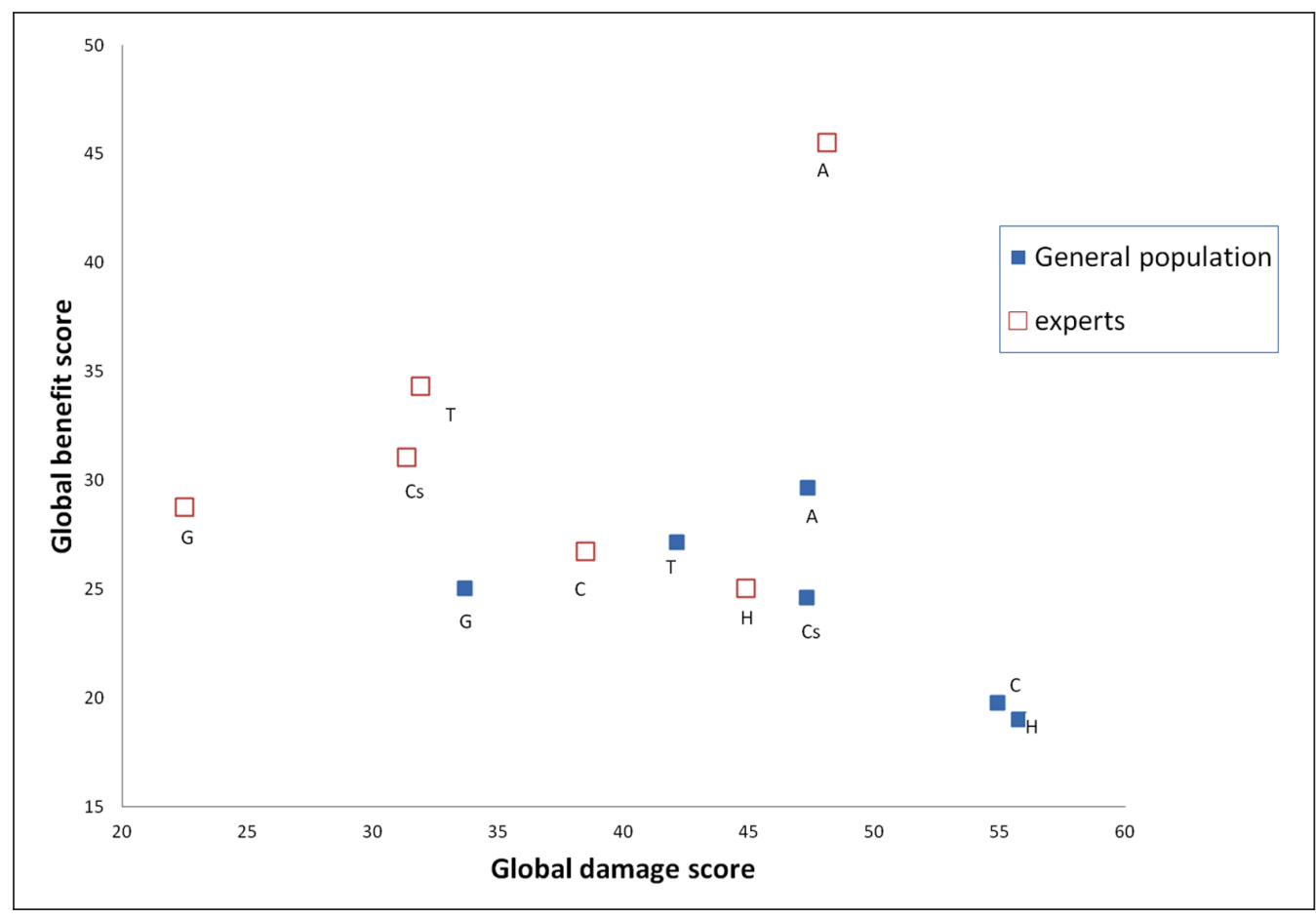

Figure 5. Global benefit scores vs global damage scores, by the general population (filled squares) and by experts (white squares). A: alcohol; T: tobacco; C: cocaine; Cs: cannabis; H: heroin; G: gambling.

-0.91 , suggesting that experts too tend to associate low benefit scores with substances with high damage scores.

\section{Discussion}

The general French population between the ages of 18-64 years quantitatively overestimated damage to both users and society associated with addictive substances and underestimated the benefit for users, compared with the evaluations of addiction experts. Alcohol was the one exception to these findings, with quantitative evaluations of damage to the users and to society by lay people very similar to those of experts. With respect to the relative dangerousness of substances, our study showed that heroin and cocaine were perceived to be the two most dangerous substances, not only because of their impact on the user but also because of the legal, social and public health impacts of use on society, and that the public showed little difference in the perceptions of these two substances. Alcohol ranked third, with a global burden judged to be only slightly above that of cannabis for its effects on users and society. For experts, however, alcohol is the substance with the highest associated damage, followed by heroin which was way ahead of cocaine. In addition, we showed that individuals who had a history of a given substance use within the past year perceived the damage and the benefit in a way that was much more congruent with the perceptions of experts compared with individuals with no history of consumption of that substance, including a concordant harm ranking of the substances.

The reasons for the particular perception of alcohol damage among the general population are certainly complex. The use of this substance is widespread and is generally socially accepted. Personal experiences with the effects of alcohol, on oneself for the users and on others for non-users, are thus frequent. The knowledge brought by these experiences could explain why the gap with expert damage evaluations seems to be bridged. On the other hand, because the public knowledge on heroin, cocaine, cannabis and tobacco damages largely differs from that of experts, alcohol turns out not to be considered as the most harmful substance, in outright contradiction to the experts.

The knowledge that drug users have of the harms associated with the substances that they use has already been documented (Morgan et al., 2009). However, these surveys, conducted with drug users only, were not able to evaluate whether this knowledge was specific to users or not. With a large sample constructed to be representative of the general population, that included information on substance consumption, we were able to compare the damage perceptions among users and non-users for each of the six substances studied and we showed how user perceptions were systematically closer to experts, for both legal and illegal substances. The statistical significance of our results should however be considered with caution. A drawback of our study design, which was population-based rather than selectively oriented on substance use habit, is that it lacked power to contrast groups of users and non-users for the substances with a low population prevalence (heroin, cocaine and cannabis to a lesser extent). Complementary studies will have to be conducted with equal numbers of users and non-users of all substances, in order to precise the statistical validity of these results.

Similarly, we were able to show that the perception of user benefit was higher among substance users than among non-users. However, interestingly, the legal status of substances seems to have an influence on these benefit perceptions. The difference observed in user benefit evaluations between users and non-users 
was larger for cocaine and cannabis than for alcohol, tobacco or gambling (no data for heroin). This result suggests that when individuals choose to use a substance, despite the existence of laws preventing its use, they are more likely to balance its damage and benefit. Consequently, awareness of benefit might be more important for them than for non-users who did not make the same choice. These findings have important implications. If approaches based on decisional balances are commonly used to treat patients with substance-use disorders, our results suggest that they could also be effective for early educational interventions on risk management for users. Indeed, interventions that ignore the potential benefit associated with use and present unbalanced views focused on the damage associated with substance use alone have little chance of convincing users, who have just become aware of the benefit, to stop using the substance.

Analyzing our results in the light of psychological studies that have compared risk perceptions by lay people with risk assessments by experts in more general contexts (Sjöberg, 2000; Slovic, $1987,2000)$ is stimulating. These studies have shown how risks may be misjudged by non-specialists. The mental strategies employed to make sense out of uncertain situations are potentially subjected to large and persistent bias, generated by lack of knowledge but also by misleading personal experience, difficulties in understanding probabilities, anxiety (Kahneman et al., 1982). In our case, this would suggest that the difference in damage evaluation between expert and lay people should not be interpreted only as a lack of knowledge by the latter.

In our previous study among French experts in addiction, we have described how their perception of the benefits of addictive substances appear to have a major impact on their general opinion of those substances. This result was in line with psychological studies that suggest a general tendency of people, including experts, to be willing to tolerate higher risks from activities seen as highly beneficial (Starr, 1969). In the present study, we observe that the lay people's perception of overall damage is negatively correlated with their perception of overall benefit (with alcohol and gambling as outliers). A stimulating hypothesis, integrating these different aspects, would be that in lay people with little knowledge on substance effects, the perception of benefit directly influences the perception of damage and not only their general opinion as for the experts. Substances with low perceived benefit are more easily considered as dangerous substances, whereas substances with higher perceived benefit are credited with lesser damage. Further data will be necessary to test this hypothesis. However, it could well be a valuable additional explanation for the gap between experts and the general public perception of damage.

The random sampling in our survey was stratified to match the official French census statistics for gender, age, occupation, population size in the area of residence, and region (Institut national de la statistique et des études économiques (Insee), 2006). However, we cannot assure that our web-based sampling strategy did not limit the population representativeness of our study. Given the fact that most of the French adult population has access to the Internet $(>81 \%$ of individuals $<59$ years had Internet access at home in 2011; Bigot and Croutte, 2012), the potential bias introduced by our sampling strategy was likely to be quite minor. Online surveys share with other survey methods the general limitations that the results are based on patients' self-reports, but it is well established that self-administered questionnaires tend to yield fewer reports in the socially desirable direction than do interviewer-administered questionnaires. Accordingly, a recent study suggested that online surveys may have the lowest social desirability bias (Kreuter et al., 2008). Still, the present study only describes perceptions of the French population. Further studies in other countries are needed.

\section{Conclusion}

The overestimation of damage for all substances, with the exception of alcohol, by the general population suggests that prevention campaigns focused on damage alone have reached their limits.

On the other hand, this certainly is a key factor to explain why illicit drugs have a much higher priority in political agendas (regarding care, research, education) than alcohol (Mann, 2012). Awareness of the perceptions of benefit of substance use among users of illegal substances suggests that we should take this into account in early interventions.

\section{Acknowledgements}

The authors are grateful to Gisèle Gilkes-Dumas and the French Federation on Addiction for administrative assistance and to Laila Idtaleb (Ipsos Santé) for her efficient supervising of the online survey.

\section{Contributors}

MR coordinated the study. MR, AL, HJA and CB designed the study. AL and $\mathrm{MR}$ adapted the damage criteria grid for a lay audience. CT organized and coordinated the online survey. $\mathrm{CB}$ and $\mathrm{AL}$ conducted the statistical analyses. All authors analyzed and discussed the results and wrote the manuscript.

\section{Conflicts of interest}

M Reynaud received sponsorship to attend scientific meetings, speaker honoraria and consultancy fees from Lundbeck, Reckitt-Benkiser, D\&A Pharma, Ethypharm, Bioprojet and Merck-Serono. H-J Aubin has received sponsorship to attend scientific meetings, speaker honoraria and consultancy fees from Pfizer, Lundbeck, D\&A Pharma, Ethypharm, Bioprojet and Merck-Serono. C. Talon is employed by Ipsos Santé, the survey research firm that organized the on-line survey. C Bourgain and A Luquiens have no conflicts of interest.

\section{Funding}

The present study was funded by the City of Paris and the Regional Council of Ile de France. The sponsors of the study had no role in the study design, data collection, data analysis, data interpretation or writing of the report.

\section{References}

Beck F, Guignard R, Richard JB, et al. (2011) Les niveaux d'usage des drogues en France en 2010. Tendances 76: 1-6.

Bigot R and Croutte P (2012) La Diffusion des Technologies de l'Information et de la Communication dans la Société Française. [Diffusion of information and communication technologies in the French society]. Paris: Crédoc.

Blendon RJ and Young JT (1998) The public and the war on illicit drugs. JAMA 279: 827-832.

Bourgain C, Falissard B, Blecha L, et al. (2012) A damage/benefit evaluation of addictive product use. Addiction 107: 441-450.

Costes JM, Le Nézet O, SS, et al. (2010) Dix ans d'évolution des perceptions et des opinions des Français sur les drogues (1999-2008). Tendances 71: 1-6. 
Eurobarometer (2010a) EU Citizen's Attitudes Towards Alcohol. Special Eurobarometer, 331. http://ec.europa.eu/health/eurobarometers/ (accessed 18 April 2013).

Eurobarometer (2010b) Tobacco. Special Eurobarometer, 332. http:// ec.europa.eu/health/eurobarometers/ (accessed 18 April 2013).

European Monitoring Centre for Drugs and Drug Addiction (EMCDDA) (2010). Statistical Bulletin 2010. http://www.emcdda.europa.eu/stats 10 (accessed 18 April 2013).

European Monitoring Centre for Drugs and Drug Addiction (EMCDDA) (2012). Statistical Bulletin. http://www.emcdda.europa.eu/stats12 (accessed 18 April 2013).

Institut national de la statistique et des études économiques (Insee) (2006) Résultats du Recensement de la Population-2006 [Results of the French census-2006]. Paris: Insee.

Kahneman D, Slovic P and Tversky AE (1982) Judgment Under Uncertainty: Heuristics and Biases. New York and Cambridge: Cambridge University Press.

Kreuter F, Presser S and Tourangeau R (2008) Social desirability bias in CATI, IVR, and Web surveys. The effects of mode and question sensitivity. Public Opin Q; 72: 847-865.

Mann KF (2012) Why should we need a European Federation of Addiction Societies? Addiction 107: 692-693.

Miller WR and Rollnick S (2002) Motivational Interviewing: Preparing People for Change. 2nd edition, New York: The Guilford Press.

Morgan CJ, Muetzelfeldt L, Muetzelfeldt M, et al. (2009) Harms associated with psychoactive substances: Findings of the UK National Drug Survey. J Psychopharmacol 24: 147-153.

Nutt DJ, King LA and Phillips LD (2010) Drug harms in the UK: A multicriteria decision analysis. Lancet 376: 1558-1565.
Nutt D, King LA, Saulsbury W, et al. (2007) Development of a rational scale to assess the harm of drugs of potential misuse. Lancet 369: 1047-1053.

Obot IS (2011) Improved ranking of drugs on harmfulness can bring sense and order to a failed system. Addiction 106: 1894-1895; discussion 1896-1898.

Pousset MEA(2012) Drogues: Chiffres Clés. 4th ed. St Denis: OFDT.

R Development Core Team (2011) R: A Language and Environment for Statistical Computing. Vienna, Austria: R Foundation for Statistical Computing.

Rossow I (2011) Can harm ratings be useful? Addiction 106: 1893-1894; discussion 1896-1898.

Schwarzinger M, Flicoteaux R, Cortarenoda S, et al. (2010) Low acceptability of $\mathrm{A} / \mathrm{H} 1 \mathrm{~N} 1$ pandemic vaccination in French adult population: did public health policy fuel public dissonance? PLoS One 5: e10199.

Sjöberg L (2000) Factors in risk perception. Risk Analysis 20: 1-11.

Slovic P (1987) Perception of risk. Science 236: 280-285.

Slovic P (2000) The Perception of Risk. London: Earthscan.

Starr C (1969) Social benefit versus technological risk. Science 165: 1232-1238.

Storvoll EE, Rossow I and Rise J (2010) Alkoholpolitikken og opinionen. Endringer i Befolkningens Holdninger til Alkoholpolitikken og Oppfatninger om Effekten av Ulike Virkemidler i Perioden 20052009 [Alcohol policy and public opinion. Changes in attitudes to alcohol policy and perceptions of effectiveness of various policy measures over the period 2005-2009]. Oslo: Norwegian Institute for Alcohol and Drug Research (SIRUS).

Van Amsterdam J, Opperhuizen A, Koeter M, et al. (2010) Ranking the harm of alcohol, tobacco and illicit drugs for the individual and the population. Eur Addict Res 16: 202-207. 